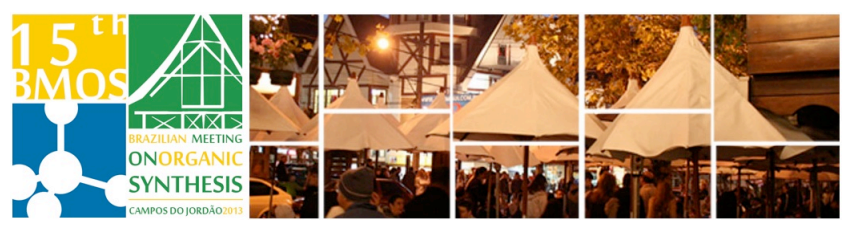

\title{
Synthesis of novel Imidazolidinone Peptidomimetics
}

\author{
Susann H. Krake and Stephen C. Bergmeier* \\ Department of Chemistry and Biochemistry, Ohio University, Athens, OH 45701, USA \\ *bergmeis@ohio.edu
}

Keywords: Peptidomimetics, Imidazolidinones, Fused Ring Aziridines

\section{INTRODUCTION}

Type 1 peptidomimetics are compounds that closely resemble peptides and their activity, but contain variations along the peptide backbone to enhance their stability towards metabolism. Compound 1 contains four such variations, as can be seen by comparison with the corresponding amino acid chain FGGF (Figure 1).

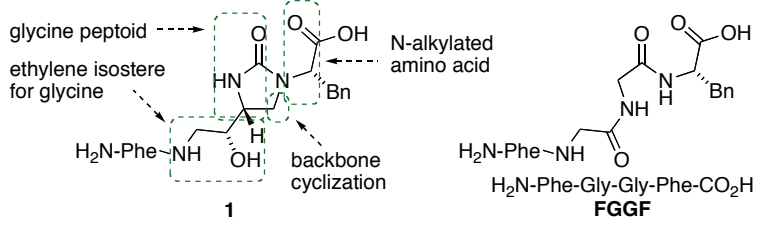

Figure 1. Peptidomimetic motifs.

The aim of this project is the development of a synthetic route to obtain a new class of peptidomimetics with scaffold $\mathbf{A}$, containing both imidazolidinones and hydroxyethylene isosteres. The key step in the synthesis is the ring opening and rearrangement of fused ring aziridine $\mathbf{2}$ with an $\alpha$-aminoamide (Scheme 1).

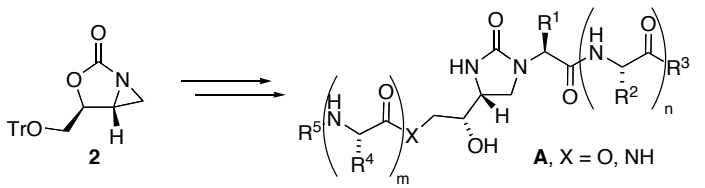

Scheme 1. Target scaffold A.

\section{RESULTS AND DISCUSSION}

The opening of aziridine $2^{1,2}$ with benzyl amide resulted in oxazolidinone intermediate 3 , which was rearranged into imidazolidinone 4 . This reaction was previously described, ${ }^{3}$ and now optimized for basefree conditions (Scheme 2).

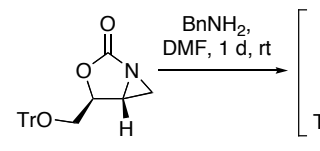

$(4 S, 5 R)-2$

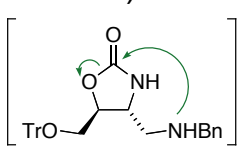

3

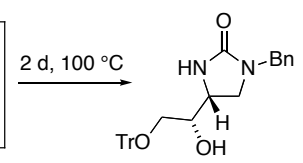

$\left(2 S, 4^{\prime} R, 1^{\prime \prime} S\right)-4,78 \%$
Scheme 2. Oxazolidinone rearrangement.

An initial opening of enantiomerically pure $\mathbf{2}$ with $L$-phenylalanine benzylamide followed by the rearrangement at elevated temperature in a one-pot procedure resulted in $\mathbf{5}$ as a single enantiomer in good yield (Scheme 3 ). While no racemization of the amino acid residue could be observed at $100^{\circ} \mathrm{C}$, heating to the boiling point of DMF as well as the addition of base to promote the rearrangement resulted in a complex reaction mixture.

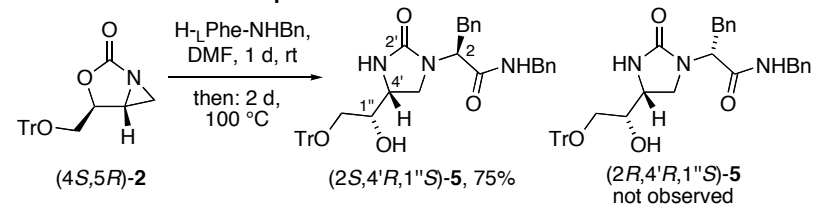

Scheme 3. Isomerization study.

Application of the described conditions for the opening with different amino acids and small peptides resulted in enantiomerically pure imidazolidinones in moderate to very good yields. Finally, complete deprotection led to the desired products in moderate yields after HPLC-purification (Table 1).

Table 1. Aziridine opening and complete deprotection.

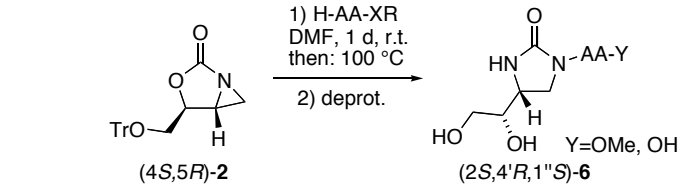

\begin{tabular}{ccccc}
\hline entry & H-AA-XR & $\begin{array}{c}\text { yield } \\
\text { step 1 }\end{array}$ & $\begin{array}{c}\text { step 2 } \\
\text { cond. }\end{array}$ & $\begin{array}{c}\text { yield } \\
\text { step 2 }\end{array}$ \\
\hline 1 & H-LPhe-OMe & $98 \%$ & $\mathrm{~A}$ & quant. \\
2 & H-LVal-OMe & $70 \%$ & $\mathrm{~A}$ & $61 \%$ \\
3 & H-LPhe-OtBu & quant. & $\mathrm{B}$ & $37 \%$ \\
4 & H-LAla-OtBu & $71 \%$ & $\mathrm{C}$ & $64 \%$ \\
5 & H-LSer(tBu)-OtBu & $70 \%$ & $\mathrm{C}$ & $57 \%$ \\
6 & H-LLys(Boc)-OtBu & $70 \%$ & $\mathrm{~B}$ & $67 \%$ \\
7 & H-Gly-LPhe-OtBu & $55 \%$ & $\mathrm{~B}$ & $48 \%$ \\
8 & H-LVal-LPhe-OtBu & $48 \%$ & $\mathrm{~B}$ & $55 \%$ \\
9 & H-Gly-LVal-LPhe-OtBu & $33 \%$ & $\mathrm{~B}$ & $77 \%$
\end{tabular}

A) $\mathrm{BF}_{3} \cdot \mathrm{Et}_{2} \mathrm{O}, \mathrm{MeOH}, \mathrm{CH}_{2} \mathrm{Cl}_{2}$; B) TPW, $\mathrm{CH}_{2} \mathrm{Cl}_{2}$; C) TPW. $\mathrm{TPW}=\mathrm{TFA} / \mathrm{PhOH} / \mathrm{H}_{2} \mathrm{O}(92.5 / 5 / 2.5)$

\section{CONCLUSION}

We were able to demonstrate a straightforward synthesis of novel peptidomimetics containing an imidazolidinone using amino acids and small peptides with a variety of functional groups, without loss of stereoinformation.

\section{ACKNOWLEDGEMENTS}

We are grateful for the Ohio University, Biomolecular Innovation and Technology Project

\section{REFERENCES}

${ }^{1}$ Bergmeier, S. C.; Stanchina, D. M., J. Org. Chem. 1999, 64, 2852-2859.

${ }^{2}$ Orac, C. M.; Zhou, S.; Means, J. A.; Boehm, D.; Bergmeier, S.

C.; Hines, J. V., J. Med. Chem. 2011, 54, 6786-6795.

${ }^{3}$ Maciagiewicz, I. M.; Fang, F.; Roberts, D. A.; Zhou, S.; Hines, J.

V.; Bergmeier, S. C., Synthesis-Stuttgart 2012, 44, 551-560. 